\title{
MECANISMOS DE CONSULTA A LOS PUEBLOS INDÍGENAS EN EL MARCO DEL CONVENIO 169 DE LA OIT: \\ EL CASO MEXICANO
}

\section{Elisa Cruz Rueda}

SAIAC OAXACA

\begin{abstract}
RESUMEN
El entender la consulta como derecho ciudadano que conlleva el consentimiento previo e informado sobre temas que afectan a la ciudadanía, y sobre todo como derecho colectivo de los pueblos indígenas, incluidos los de México, no ha sido desarrollado hasta el momento. La intención de este trabajo es argumentar la necesidad del reconocimiento de este derecho y cómo en la práctica los pueblos indígenas han sido afectados en sus territorios al no ser consultados. En el mismo sentido, se hace un análisis que toma como referentes el Convenio 169 para Pueblos indígenas y tribales en países independientes, de la Organización Internacional del Trabajo, y la Constitución Política de los Estados Unidos Mexicanos. Finalmente se comparte una propuesta de consulta a pueblos indígenas.
\end{abstract}

Palabras clave: Derechos, pueblos indígenas, instrumentos jurídicos, corresponsabilidad, diálogo intercultural. 


\begin{abstract}
Understanding has not been developed to date regarding the right to consultation as a citizen right that implies prior and informed consent by citizens regarding issues affecting them, and in particular as a collective right of indigenous peoples, including the indigenous peoples of Mexico. The intention of this document is to argue the need for recognition of this right and to discuss how territorial rights of indigenous peoples have been affected in practice due to lack of consultation. In this same sense, an analysis is presented with references to the International Labor Organization (ILO) Agreement 169 on indigenous and tribal peoples in independent countries, and to Mexico's Constitution. Finally, a proposal is presented regarding consultation of indigenous peoples.
\end{abstract}

Key words: Rights, indigenous peoples, legal tools, shared responsibility, intercultural dialogue.

\title{
INTRODUCCIÓN
}

El interés en desarrollar este tema surge a raíz de los reclamos y demandas de los pueblos indígenas, de sus organizaciones y pueblos, de ser partícipes en el diseño e implementación de planes y programas que les afectan directa e indirectamente. Tales reclamos se han intensificado desde la década de 1990 y principios de este siglo, debido a la ejecución de lo que se conoce como Plan Puebla Panamá y el Área de Libre Comercio de las Américas, ejemplo tangible es el corredor eólico en terrenos del Ejido La Venta, municipio Juchitán de Zaragoza, en el Istmo de Tehuantepec, Oaxaca; proyecto ejecutados y denominado central eólica La Venta I y II —proyectándose La Venta III y IV, véase página de Internet de la Comisión Federal de Electricidad: «La Venta. Primera central eólica». ${ }^{1}$

Si bien existe un ámbito jurídico internacional que contempla el respeto a los derechos de los pueblos indígenas, entre otros el derecho a la consulta, en el marco jurídico mexicano no está legislado ni reglamentado, circunstancia que hace que este derecho sea un concepto manejado de manera ambigua — sobre todo por los agentes gubernamentales-. 
El resultado son múltiples experiencias de no llevarse a cabo la consulta y sus consecuentes efectos negativos, de esta manera el gobierno mexicano ha respetado poco esta forma de participación como derecho de los ciudadanos en general y de los pueblos indígenas específicamente. ${ }^{2}$

Algunos ejemplos de No Consultas:

- Presa hidroeléctrica de San Juan Tetelcingo, Guerrero.

- Carretera Oaxaca-Istmo-Huatulco.

- Complejo turístico de Huatulco.

- Introducción de gasoductos en terrenos ejidales y comunales.

- Construcción de presas e hidroeléctricas.

- Construcción de refinerías y puertos marítimos.

La propuesta de mecanismo de consulta que se expone surge a propósito de una reclamación presentada ante la Organización Internacional del Trabajo por varias comunidades del Istmo de Tehuantepec — asesoradas por el Centro de Derechos Humanos Tepeyac-, en contra del Estado mexicano, concretamente contra el gobierno de Oaxaca y el gobierno federal. ${ }^{3}$

Si bien la reclamación no presenta el mecanismo, propone, entre otras cosas: «que el Estado mexicano, como parte del Convenio 169 de la OIT, establezca los mecanismos y procedimientos legales de una consulta con la asistencia del Alto Comisionado de Naciones Unidas para los Derechos Humanos, así como con el concurso de la OIT. De igual forma, se solicita que los proyectos que se estén ejecutando y se ejecuten en el Istmo sean suspendidos hasta en tanto no se definan los mecanismos mencionados, y que se resuelva el rezago agrario».

Así, son dos las fuentes fundamentales de las que se deriva esta propuesta. Primero, las denuncias y demandas de lo que no les ha parecido correcto a los indígenas, sus pueblos y organizaciones, afectados por la implementación de proyectos de desarrollo gubernamentales. Segundo, y de igual forma, los métodos de resolución de conflictos y 
los procesos de negociación antes y después de los Acuerdos de San Andrés —entre el EZLN y el gobierno federal mexicano y del estado de Chiapas (cfr. Chambers 1997)—; además de dos procesos de construcción de presas en México. Con ello se plantean las siguientes preguntas iniciales:

- ¿Por qué consultar a los pueblos indígenas en el caso de México?

- ¿Con base en qué normas y reglas se propone una consulta?

- ¿Qué diferencia existe entre las nociones de referéndum y plebiscito con la de consulta?

\section{¿POR QUÉ CONSULTAR A LOS PUEBLOS INDÍGENAS?}

Según estadísticas de instituciones gubernamentales mexicanas como la Comisión Nacional para el Desarrollo de los Pueblos Indígenas - lo que antes era el Instituto Nacional Indigenista-, los territorios que ocupan los pueblos indígenas son fuente de riqueza, sobre todo de agua, también conforman el sector más desprotegido en materias como la procuración e impartición de justicia, salud, vivienda y educación (cfr. Programa Nacional para el Desarrollo de los Pueblos Indígenas 2001-2006, en http://cdi.gob.mx/index.php?id_seccion=7).

La reclamación a la que nos referimos al principio de este trabajo fue presentada por la Coordinadora de Pueblos Indígenas del Istmo a través del Frente Amplio del Trabajo, pero al no ser reconocido éste como sindicato por la Organización Internacional del Trabajo se logró por la intermediación del Sindicato de Trabajadores de la Industria Metálica, Acero, Hierro, Conexos y Similares (STIMACHS), ya que la suscribió y presentó. La reclamación fue aceptada y actualmente se encuentra en análisis de la comisión de expertos de esta agencia internacional. Fundamentalmente consiste en la denuncia en contra de actos del gobierno federal mexicano y del estado de Oaxaca, por la cláusula federal, concretamente por la construcción de la llamada supercarretera OaxacaIstmo-Huatulco, así como por la construcción de una hidroeléctrica en la presa Presidente Benito Juárez, en Jalapa del Marqués, y otros actos y proyectos, pasando por alto la consulta que se establece en el Convenio 169 de la OIT. 
Proyectos de desarrollo como los que fueron denunciados se han implementado en la región del Istmo mexicano, en el contexto del Plan Puebla Panamá o fuera de él, con el argumento de que fueron aprobados con anterioridad al sexenio de Vicente Fox, 20002006, sin ser sometidos a la consulta de los afectados.

Para evitar estas situaciones, más adelante se comparte una propuesta de consulta a los pueblos indígenas, misma que se fundamenta en los artículos 6 y 7 del Convenio 169 de la OIT.

\section{CONSTRUCCIÓN DE LA CONFIANZA COMO PRINCIPIO DE LA CONSULTA}

Por mucho tiempo, en México como en otros países del continente, los indígenas y sus pueblos han sido marginados y discriminados. Un reflejo de esto es que el Estado mexicano ha pasado por alto el derecho que tienen a ser consultados sobre aquellos asuntos que afectan las vidas de los que ahí viven. Por esto, no es gratuito que la falta de consulta a los pueblos indígenas los ha predispuesto a rechazar cualquier iniciativa gubernamental, sea que ponga en riesgo su supervivencia o no. La acción y reacción de los indígenas, sus pueblos y organizaciones, también se explica por la relación que el Estado mexicano ha establecido con ellos, así como con la sociedad mexicana en general.

La intención de este trabajo es dar cuenta de los ejemplos de no consulta así como de una propuesta de consulta, más que el analizar esa relación que se expresa en la política indigenista, sin embargo es necesario precisar que varios autores ya han dado cuenta de ella, así como de los cambios que las organizaciones indígenas y los propios indígenas han tenido después de más de sesenta años de esa política (cfr. Díaz-Polanco1992, Del Val 1997, Favre 1999, Pérez y Argueta 2003; Hernández, Paz y Sierra 2004) ${ }^{4}$. De esta manera, y a diferencia de hace cincuenta años, los indígenas de ahora exigen interlocución y participación activa, ya no desde lo que dicta el Estado sino desde lo que se decide en sus comunidades y regiones. Exigen espacios de diálogo y negociación en los que se discuta el problema, con la convicción de que esto no solo sea «tomado en 
Revista Pueblos y Fronteras digital

Estudios, aportes y retos actuales de la antropología jurídica en México
Núm. 5, Junio-Noviembre 2008 http:// www.pueblosyfronteras.unam.mx

cuenta», sino que defina efectivamente las decisiones del Estado en sus tres niveles de gobierno y poderes. ${ }^{5}$

Como se ha mencionado, el desprestigio se centra fundamentalmente en que los proyectos que han afectado y dañado a los pueblos indígenas — presas, gasoductos, carreteras, centros turísticos...- no han sido consultados, o incluso después de haberse llevado a cabo presentan riesgos o efectos negativos al entorno, y tampoco se pone a consideración su viabilidad y grado de seguridad a futuro.

\section{TRAZOS DE LA SUPERCARRETERA OAXACA- ISTMO- HUATULCO.}

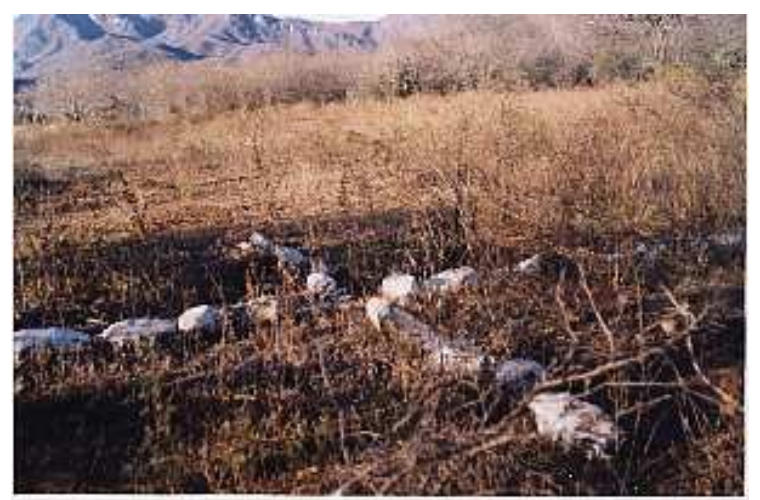

COMUNIDAD: SANTA MARIA ZAPOTITLAN, Municipio de ECATEPEC, OAXACA.

- En estas fotos se pueden observar las marcas que la Secretaría de Comunicaciones y Transportes realizó sin dar aviso y mucho menos consultar a las comunidades afectadas. Lo que causó

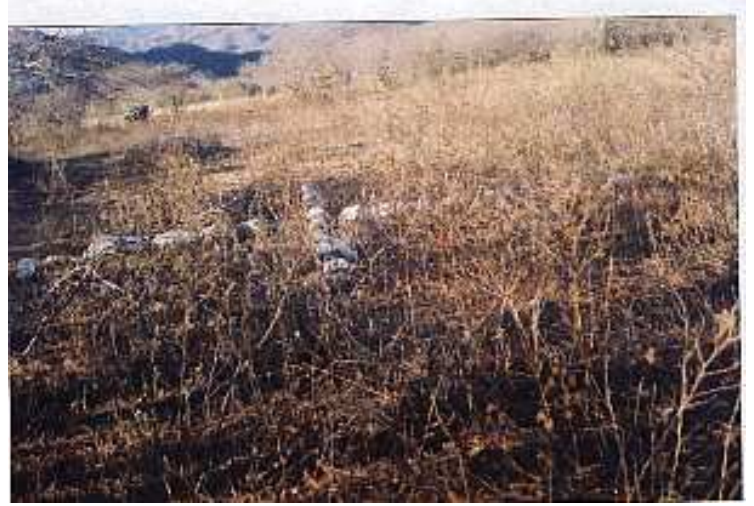
mucha zozobra e incertidumbre entre los pobladores. 
TRAZOS DE LA SUPERCARRTERA OAXACA- ISTMO- HUATULCO.

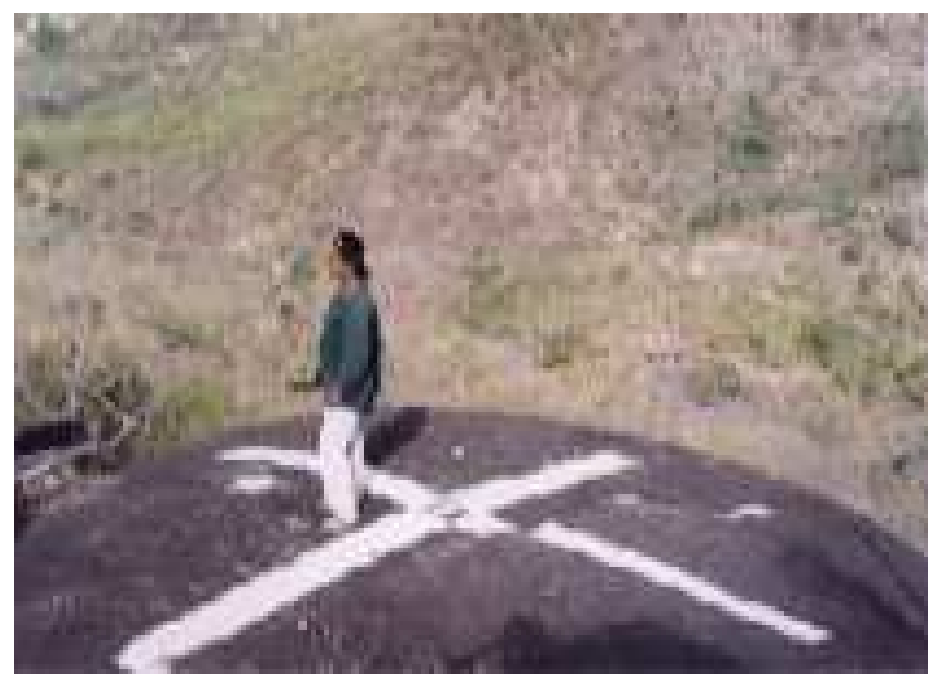

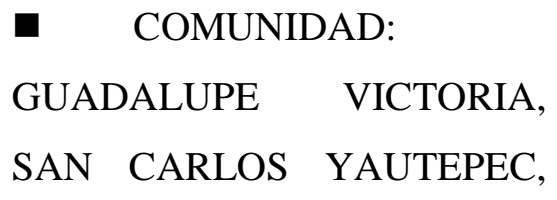
OAXACA.

En estas circunstancias, los pueblos indígenas y sus organizaciones perciben que las consultas son impuestas, unilaterales e improvisadas o hechas al vapor, además que el resultado ha sido utilizado por el Estado para ensalzar y legitimar un discurso de respeto a los derechos de los pueblos indígenas, cuando en los hechos se constata lo contrario: verbi gratia, en la impartición de justicia del Estado en regiones indígenas no se contempla el respeto a las formas de organización ni de elección de autoridades, además los niveles de vida de los indígenas son muy bajos, sumado a la alta migración que presentan — por buscar mejores ingresos y condiciones de vida.

Las consultas se presentan, para los indígenas, ${ }^{6}$ sus pueblos y organizaciones, más como un discurso de legitimación de la política del Estado mexicano en el ámbito internacional que como una oportunidad de construir confianza y diálogo — ver lo que ocurrió con los Acuerdos de San Andrés, cuando el gobierno mexicano los presentó en la ONU como una prueba de su política de respeto a los derechos humanos.

De igual forma, cuando el gobierno convoca «consultas» no se da seguimiento a la interlocución que se establece o se pretendía establecer, por ejemplo, la discusión con las 
comunidades, pueblos y organizaciones, sobre los alcances y grado de vinculación de los resultados: el cómo serán aplicados o interpretados, sus efectos.

En conclusión, las consultas tienen un punto débil, pues al no quedar claro los compromisos del Estado o de las instituciones gubernamentales que las aplican o ejecutan, se generan en los consultados expectativas que muchas veces no son previstas por los funcionarios y representantes estatales. Esto sucede porque no se planteó desde sus dependencias un beneficio claro para los consultados, o bien porque el diseño no se hizo bajo un esquema de negociación e interlocución bilateral sino de una manera unilateral e impositiva, es decir, no se consideran el diálogo ni el acuerdo bilateral como elementos fundamentales de una consulta en sus distintas fases.

\section{ESTABLECER UNA NUEVA RELACIÓN ENTRE EL ESTADO Y LA SOCIEDAD}

\section{CON LOS PUEBLOS INDÍGENAS}

La política indigenista, como relación que el Estado mexicano ha establecido con los pueblos indígenas, está desprestigiada, por lo que los indígenas, sus pueblos y organizaciones, tienen reservas y suspicacias sobre los programas, propuestas y consultas que hace el gobierno a través de sus agentes: funcionarios, autoridades, representantes, servidores públicos.

Una nueva relación implica hablar de un nuevo Estado con una nueva política indigenista, de una nueva sociedad con nuevas actitudes, positivas, hacia los indígenas, y de nuevos pueblos indígenas que controlen su destino, empoderados, en constante diálogo con las otras partes de la relación (véase segunda parte del Programa Nacional para el Desarrollo de los Pueblos Indígenas 2001-2006, de la Comisión Nacional Para el Desarrollo de los Pueblos Indígenas).

Desde la parte indígena, se trata de trabajar la nueva relación desde el fortalecimiento y revaloración de las comunidades, como sujetos operantes de los pueblos indígenas y unidad primigenia y básica de los mismos, en la que confluyen las distintas expresiones 
de organización y relaciones humanas —familia, relaciones de parentesco, los cargos, las autoridades, los individuos, las organizaciones sociales y económicas-. Esta revaloración será enfocada hacia la constitución de nuevos pueblos indígenas, reconstituidos y fortalecidos desde sus miembros y siguiendo sus aspiraciones, donde ellos y sus comunidades tengan el control de su propio destino.

\section{NECESIDAD DE UN MARCO JURÍDICO INTERNO SOBRE LA CONSULTA A LAS COMUNIDADES,}

\section{PUEBLOS Y ORGANIZACIONES INDÍGENAS}

Para lograr una nueva relación entre el Estado y la sociedad mexicana con los pueblos indígenas, es necesario establecer la confianza y trabajar una propuesta legal sobre cómo realizar una consulta, que implica fundamentalmente el reconocimiento y respeto de una de las reivindicaciones que los pueblos en el ámbito internacional han planteado, como es el consentimiento previo e informado - principio fundamental de la propuesta de consulta que aquí se presenta.

La consulta está planteada como derecho de los pueblos indígenas y obligación del Estado en los artículos 6 y 7 del Convenio 169 de la Organización Internacional del Trabajo. En este instrumento internacional, la consulta no se acota o limita a determinados temas o aspectos, ni tampoco a un ámbito comunitario, municipal, regional, estatal, federal. Sin embargo, en lo jurídico nacional este derecho no está regulado. En las últimas reformas constitucionales federales en materia indígena - la llamada ley indígena de 2001—, el carácter amplio de la consulta establecido internacionalmente se trunca y limita (artículo 2, fracción IX del apartado B).

Artículo $2^{\circ}$.- La Nación Mexicana es única e indivisible.

B. La Federación, los Estados y los Municipios, para promover la igualdad de oportunidades de los indígenas y eliminar cualquier práctica discriminatoria, establecerán las instituciones y determinarán las políticas necesarias para garantizar la vigencia de los derechos de los indígenas y el desarrollo integral de sus pueblos y comunidades, las cuales deberán ser diseñadas y operadas conjuntamente con ellos. 
Para abatir las carencias y rezagos que afectan a los pueblos y comunidades indígenas, dichas autoridades, tienen la obligación de:

IX. Consultar a los pueblos indígenas en la elaboración del Plan Nacional de Desarrollo y de los estatales y municipales y, en su caso, incorporar las recomendaciones y propuestas que realicen.

De igual forma en el artículo 26 de la Constitución Política de los Estados Unidos Mexicanos se refiere a la consulta en general enfocada a los planes y programas de desarrollo; aunque las veces que se ha realizado ha sido de manera unilateral, desde su diseño y ejecución hasta el seguimiento de los resultados.

Ciertamente el Convenio 169 de la Organización Internacional del Trabajo solo establece dos características para una consulta: que sea adecuada y de buena fe; no se abunda en los mecanismos y procedimientos, tampoco se establecen lineamientos, por lo que se puede interpretar que todo puede entenderse dentro de este género: desde la celebración de una asamblea, un sondeo de opinión, encuestas, foros, talleres, hasta los censos de población y vivienda o los censos económicos. ${ }^{7}$

Lo anterior plantea la necesidad de un marco jurídico constitucional nacional en el que se establezca el derecho y la exigibilidad de una consulta de buena fe, en el entendido de que el detalle de los mecanismos de exigibilidad deberá ser reglamentado con una ley secundaria. A partir de la definición de reglas y procedimientos claros, para no dejar lugar a duda o ambigüedades sobre lo que debe entenderse por consulta, debe precisarse el carácter vinculante de la misma y sus implicaciones, esto es, los derechos, las obligaciones y los alcances. 
FUNDAMENTOS LEGALES, CONCEPTOS Y PRINCIPIOS QUE DEBEN REGIR EL PROCESO DE CONSULTA

Fundamento legal de la Consulta

- El consentimiento previo e informado como base de la consulta (Declaración Universal de los derechos de los Pueblos Indígenas 2006. Aprobada por la Comisión de Derechos Humanos y pendiente de aprobarse por el Consejo General de la ONU).

- Artículos 6 y 7 del Convenio 169 (1989) de la Organización Internacional del Trabajo sobre Pueblos indígenas y tribales en países independientes.

- Fracción IX del apartado B del artículo $2^{\circ}$. De la Constitución Federal.

- Artículo 26 de la Constitución Política de los Estados Unidos Mexicanos.

Lo anterior constituye el fundamento legal de nuestra propuesta de consulta a los pueblos indígenas. Así como se comentó anteriormente, los artículos 6 y 7 refieren la necesidad de consultar a los pueblos indígenas sobre temas y proyectos que les afecten directa e indirectamente.

\section{Art.6 Convenio 169 OIT}

1. Al aplicar las disposiciones del presente Convenio, los gobiernos deberán:

- Consultar a los pueblos interesados, mediante procedimientos apropiados y en particular a través de sus instituciones representativas, cada vez que se prevean medidas legislativas o administrativas susceptibles de afectarles directamente.

- Establecer los medios a través de los cuales los pueblos interesados puedan participar libremente, por lo menos en la misma medida que otros sectores de la población, y a todos los niveles en la adopción de decisiones en instituciones electivas y organismos administrativos y de otra índole responsables de políticas y programas que les conciernan; 
- Establecer los medios para el pleno desarrollo de las instituciones e iniciativas de esos pueblos, y en los casos apropiados proporcionar los recursos necesarios para este fin.

2. Las consultas llevadas a cabo en la aplicación de este Convenio deberán efectuarse de buena fe y de una manera apropiada a las circunstancias, con la finalidad de llegar a un acuerdo o lograr el consentimiento acerca de las medidas propuestas.

El punto dos de este artículo se puede interpretar en el sentido de que la meta a seguir es que el Estado y los pueblos indígenas lleguen a un acuerdo, a partir de una consulta adecuada o apropiada y de buena fe.

Y el artículo 7 señala:

\section{Artículo 7}

- Los pueblos interesados deberán tener el derecho de decidir sus propias prioridades en lo que atañe al proceso de desarrollo, en la medida en que éste afecte a sus vidas, creencias, instituciones y bienestar espiritual y a las tierras que ocupan o utilizan de alguna manera, y de controlar, en la medida de lo posible, su propio desarrollo económico, social y cultural. Además, dichos pueblos deberán participar en la formulación, aplicación y evaluación de los planes y programas de desarrollo nacional y regional susceptibles de afectarles directamente.

- El mejoramiento de las condiciones de vida y de trabajo y del nivel de salud y educación de los pueblos interesados, con su participación y cooperación, deberá ser prioritario en los planes de desarrollo económico global de las regiones donde habitan. Los proyectos especiales de desarrollo para estas regiones deberán también elaborarse de modo que promuevan dicho mejoramiento.

- Los gobiernos deberán velar porque, siempre que haya lugar, se efectúen estudios, en cooperación con los pueblos interesados, a fin de evaluar la incidencia social, espiritual, cultural y sobre el medio ambiente que las actividades de desarrollo previstas puedan tener sobre esos pueblos. Los resultados de estos estudios deberán ser considerados como criterios fundamentales para la ejecución de las actividades mencionadas. 
- Los gobiernos deberán tomar medidas, en cooperación con los pueblos interesados, para proteger y preservar el medio ambiente de los territorios que habitan.

Podemos decir entonces que el sentido y motivación del artículo 7 se fundamenta en el acuerdo generalizado de que el logro en la igualdad de oportunidades para el desarrollo depende de que los pueblos indígenas ejerzan un control y de que puedan administrar sus tierras y recursos naturales de manera sostenible. Entre otras cosas, eso supone consultar a las comunidades indígenas y tribales, con seriedad y buena fe, para recabar su consentimiento sobre la pertinencia de una consulta, el contenido de la misma, el impacto de las medidas económicas, sociales y ecológicas de los proyectos que las entidades públicas y privadas prevean llevar a cabo en sus territorios, entre otros temas. La consulta servirá como medio para que las comunidades indígenas intervengan en el diseño e instrumentación de las acciones y políticas públicas. Es decir, «lograr la igualdad de oportunidades implica promover la redistribución de los recursos, el acceso a las oportunidades de desarrollo, a la toma de decisiones y a la participación en el diseño e instrumentación de las acciones» (Barsh y Bastien 1997: IX). ${ }^{8}$

Por lo anterior, el artículo 7 es importante en la medida que considera los objetivos y metas de una consulta — planteada en el art. 6-, y en última instancia de las acciones del gobierno y de los tres poderes del Estado.

A través de la consulta el Estado y sus aparatos de gobierno junto con los indígenas definirán las modalidades de la participación con el objetivo de decidir sus prioridades y el proceso de desarrollo para «participar en la formulación, aplicación y evaluación de los planes y programas de desarrollo nacional y regional susceptibles de afectarles directamente», tal afectación se puede medir por el impacto y/o daño físico, espiritual, ambiental, psicológico...».

Así, del artículo 7 se deriva la necesidad de un procedimiento de diálogo para el diseño, ejecución y evaluación de los planes y programas de desarrollo económico, social y 
cultural. Según se desprende del primer punto de este artículo, el desarrollo está vinculado con un sistema de valores y creencias, y no solo con la subsistencia, recurso económico, o con la obra material o infraestructura.

De tal suerte, el desarrollo tiene que ver con las formas de vida, creencias, instituciones y bienestar espiritual, así como con el uso y posesión de las tierras y el sentido que estas tienen para los indígenas y sus pueblos.

A continuación se dan las definiciones del plebiscito, el referéndum y la consulta popular como la entiende el gobierno, para dar cuenta de las diferencias entre estas figuras con nuestra propuesta de consulta. Los dos primeros son mecanismos para la toma de decisiones del poder ejecutivo y del legislativo, respectivamente, mientras la última, es la recolección de opiniones para tomar una decisión; las cuales no tienen porque ser forzosamente asumidas por la instancia de gobierno o de Estado que las recolecta.

El plebiscito es un instrumento por medio del cual el ejecutivo pone en consideración una decisión importante (de carácter programático, legislativo o de dirección) a la población.

"La consideración tiene que ser formulada como pregunta que acepta sólo respuestas negativas o positivas, siendo obligación del ejecutivo ser consecuente con los resultados del cómputo" (Álvarez y Castro 2000:33).

El referéndum es un procedimiento parecido, pero que generalmente es impulsado por el legislativo, para el caso de aprobación, reforma o abrogación de leyes y reglamentos.

La consulta popular consiste en la recolección de opiniones diversas para tomarlas en cuenta en un proceso deliberativo.

Estos mecanismos son útiles para una consulta a pueblos indígenas, como aquí se propone, pero de ninguna manera se puede afirmar que su aplicación sea considerada 
como una consulta adecuada, porque la formulación de los temas y preguntas está hecha desde el Estado y el gobierno, sin considerar la participación de los indígenas.

\section{PROPUESTA DE CONSULTA: CARACTERÍSTICAS Y PRINCIPIOS QUE DEBE CUMPLIR UNA CONSULTA A LOS PUEBLOS Y COMUNIDADES INDÍGENAS.}

A continuación expongo una propuesta de cómo hacer la consulta a los pueblos indígenas, estableciendo primero sus características:

1. carácter vinculante, a qué se obliga el Estado y su gobierno antes y después de una consulta;

2. construcción de acuerdos con visión de proceso, la consulta es un medio y no un fin;

3. derecho de los consultados a la información para lograr el respeto del principio de consentimiento previo e informado, para hacer la consulta y para implementar los proyectos aprobados en esa consulta, o en su caso el respeto al rechazo de los mismos, 4. buena fe y adecuación a las formas de organización indígenas.

\section{CARÁCTER VinCULANTE}

El carácter vinculante, o la naturaleza vinculante de la consulta, se define como el grado de obligatoriedad que tiene para el Estado, desde el diseño e implementación hasta los resultados — seguimiento y verificación—; cómo éstos lo obligan, para qué y en qué.

Vinculación y corresponsabilidad: derechos y obligaciones que se derivan de una consulta.

En el derecho internacional público el término vinculante se refiere a las obligaciones que un Estado adquiere frente a otros Estados para cumplir un instrumento internacional que ha firmado y/o ratificado, de igual manera contempla los derechos para exigir a otro Estado el cumplimiento de esos tratados o convenios. 
Es decir, se trata de responder, entre otras cosas, a: ¿cómo y a qué se obliga el Estado cuando plantea, promueve, ejecuta o implementa una consulta? ¿Qué carácter tienen los resultados?, ¿son meramente estadísticos, informativos, de orientación o de toma de decisiones? ¿Qué sucede con los compromisos y responsabilidades que el Estado o sus dependencias asumieron en el proceso y ejecución de la consulta?, ¿hasta dónde se compromete con los resultados?

\section{LA CONSULTA PARA LA CONSTRUCCIÓN DE ACUERDOS CON VISIÓN DE PROCESO}

La consulta es un proceso que debe desarrollarse en tiempos razonables establecidos para cada etapa, no de manera improvisada y apresurada sino con visión de largo plazo. Se debe tener presente que la consulta siempre genera expectativas de toda índole. El grado de vinculación será expuesto a las comunidades indígenas desde los primeros encuentros para abrir espacios de entendimiento — construcción de la confianza- y evitar malos entendidos y conflictos a futuro.

Lo anterior será fundamental para establecer la interacción y corresponsabilidad entre gobierno/operadores y consultados/ciudadanos/pueblos indígenas/comunidades. De esta manera, en cada etapa, se deberán dar o fomentar los momentos de negociación y diálogo.

\section{DERECHO A LA INFORMACIÓN DE LOS QUE VAN A SER CONSULTADOS}

Es importante considerar que para que una consulta sea adecuada se debe «bajar»o hacer accesible a los pueblos indígenas la información sobre lo que se les va a consultar con un plazo de tiempo razonable — según la organización comunitaria — previo a la consulta.

La información ofrecida a los pueblos debe ser lo más completa posible y en sus términos, utilizando sus palabras y conceptos, planteando alcances, obstáculos, retos e implicaciones positivas y negativas — tanto para el Estado como para ellos. ${ }^{9}$ 
De esta manera, la calidad de la información que la gente tiene y se les transmite (cfr. Tomei y Swepston 1996: 9) determina la calidad de la consulta y el tipo de ésta. La calidad de la información estará dada según si la gente o comunidad tiene información sobre un tema, tanto o igual que el Estado — dependencia o funcionario-, y la puede manejar o se apropia de ella en sus términos/conceptos/palabras. Lo que nos plantea una cuestión de paridad, como principio fundamental de un diálogo entre iguales. Si el funcionario no maneja toda la información, es decir, no ha sido previa y él está poco capacitado sobre el tema en cuestión, no puede dar una visión de las ventajas y desventajas ni responder a las dudas de los consultados, entonces podría presumirse que existe mala fe por parte del Estado.

En otra etapa, el funcionario capacitará a su vez a la comunidad sobre la información que tiene —o la «bajará» al lenguaje de los implicados_-, a través de personas oriundas de la comunidad, asegurando que la información sea lo más cabal y clara posible, siendo recomendable que se realice en su propia lengua y con procedimientos didácticos comprensibles y accesibles para la población.

La calidad de la consulta estará dada por la calidad de la información vertida y el grado de apropiación que la comunidad tenga sobre la misma. La consulta será de alta calidad si cumple el requisito del derecho de la comunidad a la información sobre un tema determinado y cumple con los artículos 6 y 7 del Convenio 169 de la OIT, sobre todo con el principio del consentimiento previo e informado: la comunidad ha consentido ser consultada, está de acuerdo con las características y alcances, que pueden ser estadísticos, informáticos o vinculantes; por ejemplo, permitir que se construya una presa.

\section{LAS CONSULTAS DEBEN SER DE BUENA FE}

Previamente, se debe diferenciar entre promover un proyecto para convencer sobre su factibilidad — proselitismo - y la consulta sobre el mismo, de lo contrario puede presumirse que la consulta se hace de mala fe. 
Consulta y participación —entendida ésta como formar parte de e intervenir en — están íntimamente relacionadas: No puede haber consulta $\sin$ la participación/negociación/diálogo de las comunidades y pueblos indígenas, tampoco hay participación sin la expresión abierta y libre de la voluntad, es decir, que se dé sin vicios de mala fe, amenazas o coacción y dolo. ${ }^{10}$

La consulta que el Estado haga a los indígenas, sus comunidades, pueblos y organizaciones, se enmarca en un acto jurídico, en tanto que está establecida en un instrumento jurídico internacional donde el Estado mexicano se ha obligado con o frente a otros Estados en favor de los pueblos indígenas — mediante el Convenio 169-. Sin embargo, la especificidad de los derechos reconocidos e implicaciones de la consulta - para los ciudadanos en general y en particular para los indígenas-, debe establecerse con claridad en la Constitución y las leyes mexicanas. De esta manera, el Estado y sus dependencias tendrán cuidado de cumplir los requisitos de cualquier acto jurídico de acuerdo con el Derecho mexicano, y aplicando en lo interno el derecho internacional, la costumbre jurídica internacional, jus cogens, y sus principios jurídicos generales.

¿Qué es la buena fe?

Lo primero que se nos puede ocurrir es que la buena fe hace referencia a un precepto ético, sin embargo, cuando ha sido recogida por el Derecho interno o Derecho mexicano y el Derecho internacional, estamos hablando de un principio jurídico. De acuerdo con el diccionario jurídico mexicano, establece que la buena fe es «una locución tomada en consideración en numerosas disposiciones legales, definida como la obligación de conducirse honrada y concienzudamente en la formación y ejecución del negocio jurídico sin atenerse necesariamente a la letra del mismo» (Pérez Duarte y García Moreno 1987: 362-363). De igual forma se agrega que «los autores mexicanos, especialmente Galindo Garfias, sostienen que la buena fe es una expresión que alude al deber moral calificado de social, pero que adquiere imperatividad y coercibilidad al ser postulada como un principio de derecho en la medida en que se trasforma en regla de derecho». Luego entonces, la noción de buena fe, al ser incorporada al marco jurídico u ordenamiento 
mexicano, se vuelve un principio general del derecho, pero además «una fuente subsidiaria del mismo; una guía del intérprete en su labor doctrinal y jurisprudencial; un deber jurídico; una comunicación razonablemente fundada de que con nuestra conducta no causamos daño a otro» (cfr. Pérez y García 1987) ${ }^{11}$.

En el ámbito internacional, se habla de «bona fide» para indicar espíritu de lealtad, de respeto al derecho, y de fidelidad, es decir, como ausencia de simulación, de dolo, en las relaciones entre dos o más partes en un acto jurídico. En la interpretación y ejecución de las obligaciones internacionales significa fidelidad a los compromisos, sin pretender acrecentarlos o disminuirlos —es decir: pacta sunt servanda- El principio de la buena fe se encuentra recogido en la Carta de Naciones Unidas, artículo 2, párrafo 2, que dispone que «los Estados deberán cumplir de buena fe los compromisos contraídos» (Pérez y Moreno 1987). De igual forma, esto se encuentra estipulado en los artículos 18, 26 y 31 de la Convención de Viena sobre el Derecho de los Tratados.

Si profundizamos más, en el Código Civil Federal — artículos 2180 a 2184 — se establece que la simulación se presenta cuando el acto simulado no tiene nada de real o se oculta su verdadero carácter, dándole otra apariencia o una falsa apariencia. Por ejemplo, en el caso que tratamos, la consulta se convoca para conocer la opinión de la gente sobre la manera de cómo se organizan para la producción y desarrollo de sus comunidades o regiones, y en realidad se les pregunta si están de acuerdo con los proyectos integrados al Plan Puebla Panamá, ${ }^{12}$ o con determinados proyectos que han sido detectados así por las organizaciones sociales en general o en particular las indígenas.

En otras palabras, y siguiendo la definición arriba citada, la buena fe es el apego a la palabra empeñada y comprometida o la ausencia de manipulación en un acto jurídico. Entendemos por manipulación llevar a la comunidad o sujetos consultados a una opinión o resultado que se desea, que se ha prefigurado o diseñado de antemano, a través de varios caminos, abusando de la ignorancia de los consultados, dando información parcial, haciendo preguntas inducidas o proponiendo, abierta o veladamente, un resultado, entre otros. $^{13}$ 
La consulta debe ser diseñada con la participación de las comunidades y pueblos indígenas, tomando en cuenta su opinión, tiempos, expectativas, visión de futuro, sus creencias, inquietudes, fantasías, idioma y lenguaje.

La consulta tratará sobre decisiones ejecutivas, legislativas o judiciales, que serán tomadas en un futuro desde los tres poderes de la Unión o por el Estado en determinados temas que afectan a los pueblos indígenas. Si estas decisiones ya fueron asumidas o adoptadas antes de ser consultadas, contraviniendo el Convenio 169 de la OIT —artículos 6 y 7- existirá mala fe, y deben utilizarse herramientas y métodos de resolución de conflictos, por lo que en el marco jurídico constitucional debe establecerse la consulta como un derecho exigible e impugnable. En la o las leyes deben fijarse los mecanismos de réplica o anulación de la consulta, aun cuando después de la decisión tomada se haga una consulta que coincida con ella o la ratifique, pues el acto de voluntad está afectado por la mala fe.

La comunicación de los resultados a los sujetos consultados debe darse de la misma manera en que se realizó el diseño e implementación de la consulta, a través del diálogo y la participación con las comunidades. Es decir, la consulta es un proceso de diálogo y negociación constante y permanente, que debe darse antes, durante y después de la misma.

\section{ETAPAS DE LA CONSULTA. ASPECTOS QUE DEBEN DEFINIRSE ENTRE EL ESTADO, LOS INDÍGENAS Y SUS COMUNIDADES}

Antes del diseño de una consulta entre el Estado y los pueblos indígenas es importante considerar que previamente aquél y sus dependencias gubernamentales han definido una serie de cuestiones sobre la consulta, entre otras su carácter y su propósito; ahora se trata de que esos aspectos se compartan y de definir la participación de los indígenas, sus comunidades y pueblos. 
Como ya se comentó, el gobierno mexicano ha realizado numerosas consultas de opinión pero ninguna con el carácter que aquí se propone. Sin embargo, también es importante mencionar que se han realizado otro tipo de consultas.

Ejemplos de "consultas de opinión".

- Ley reglamentaria del primer párrafo del artículo $4^{\circ}$. Constitucional (1990) y segundo de la fracción VII del artículo 27 Constitucional (1992).

- "Consulta a los pueblos indígenas sobre sus formas y aspiraciones de desarrollo. 2003”.

Ejemplo de Consultas "exitosas".

- Presas de Aguamilpa (Nayarit 1987-1994) y Zimapam (Hidalgo).

- En estos ejemplos se tomó como base legal el Convenio 169 de la OIT (Salomón Nahmad -CIESAS/Oax- y un video testimonio del centro de información del departamento de Antropología de la UAM-I).

Por cuestiones de espacio no se hace referencia al proceso que se siguió en la construcción de las presas Aguamilpa y Zimapan, solo hago mención porque me interesa subrayar su importancia, ya que de ellos se puede sustraer lo que debe evitarse en un proceso de consulta. Es decir, estos procesos nos presentan lo que debe procurarse de un proceso que se desea participativo, intercultural, dialogal, ya sea consulta o la ejecución de proyectos de infraestructura. ${ }^{14}$ Sin duda también son útiles los casos de no consulta, como el de la presa hidroeléctrica de San Juan Tetelcingo, Guerrero, en el que los pueblos nahuas del Alto Balsas invocaron el Convenio 169, logrando que prosperara ese proyecto. ${ }^{15}$ 


\section{NEGOCIAR LA CONSULTA PARA CONSTRUIR CONFIANZA}

\section{CON LOS SUJETOS INVOLUCRADOS}

Corresponde plantearse la construcción de la confianza desde una visión ética y de responsabilidad, teniendo conciencia de lo que se plantea y promete a los representantes de los consultados: autoridades, comunidad /asamblea, líderes, intelectuales, organizaciones — con los cuales se establecerán responsabilidades.

Por lo tanto, es indispensable establecer plazos para la construcción de acuerdos, en el entendido de que es un proceso de diálogo y negociación en el que se considera como etapa fundamental de la consulta la devolución de sus resultados.

En esta propuesta se entiende por negociación, como la construcción de acuerdos entre actores que discrepan en sus posiciones —ideas o ideología, demandas, creencias, valores-, pero que los une el dar solución a situaciones sobre las que comparten intereses aunque no necesidades. Los intereses pueden cambiar a la luz de nueva información o al profundizar en la investigación de un problema o situación. De esta manera, los intereses son bienes, percepciones u otro tipo de satisfactores que pueden ser objeto de intercambio o de nuevas opciones convergentes; no así las posturas, por lo que no pueden negociarse, de lo contrario el proceso se estancará.

\section{DISEÑAR LA CONSULTA ENTRE EL ESTADO Y LOS PUEBLOS INDÍGENAS}

$$
\text { —DIÁLOGO Y NEGOCIACIÓN PREVIOS- }
$$

En un escenario ideal en el que se ha logrado que las partes del conflicto consultadas y funcionarios hayan resuelto el problema de la representación, ${ }^{16}$ y que se reconozcan con necesidades y posturas diferentes pero como parte de un problema y también de su solución, se puede pasar al diseño de la consulta. 
Como mencionábamos, el Estado y sus dependencias ya definieron y diseñaron una propuesta de consulta, con una ruta crítica y posibles conflictos para enfrentar, ahora este ejercicio deberá realizarse con los consultados. Para ello se resaltan los siguientes aspectos a tomarse en cuenta:

$>$ Preguntas previas a responder: ¿Cuántos saben leer y escribir? ¿Cuántos tienen información? ¿Cuántos están involucrados? ¿Cuántos están dispuestos a participar?

Los sectores serán consultados con base en un modelo democrático de representación o participación comunitaria: por género, por generación —edad—, por tema de interés.

Se establecerán las necesidades, planteando posibles conflictos de intereses, posturas y posiciones.

> Se definirán las expectativas — gobierno/indígenas - y capacidad de respuesta — gobierno- - tomando en cuenta la proyección de futuro de los operadores y los consultados. Así considera el imaginario de la gente que se va a consultar: fantasías, ilusiones, sentimientos, percepciones y creencias.

$>$ Proyección de plazos para informar sobre el tema de consulta, «bajando» la información sobre lo que se quiere consultar.

Responder la pregunta: ¿quiénes informarán?, así como la definición de plazos para capacitar a los agentes de la comunidad para «bajar» la información, por ejemplo si es para elaborar el Plan de Desarrollo de los Pueblos indígenas, deberán considerarse temas como:

○ Economía y desarrollo.

○ Formas de gobierno indígena: derecho indígena, sistemas normativos, ejercicio de la autoridad.

○ Participación de las mujeres.

- Justicia y derecho estatal.

- Derecho a la información

- Recursos naturales y medio ambiente.

○ Reformas constitucionales y legales. 
○ Capacitación para la información y consulta.

Así como el planteamiento y respuesta de:

○ ¿Con qué información se cuenta?

○ ¿Con qué medios se cuenta para difundir la información?

- Verbal: foros, talleres, alta voces, radio.

- Escrita: folletos, trípticos, periódicos.

- Visual: videos, televisión, historietas

Definir el método y medios para recoger datos en una preconsulta. Como indicábamos, los que han sido nombrados representantes para una consulta plantean la necesidad de regresar o volcar la información obtenida a sus representados, en este caso lo que se quiere con una consulta: su diseño, los temas y la información; y siempre solicitan o exigirán la presencia del agente externo o funcionario.

Es decir, en la proyección que se haga sobre una consulta deben definirse los temas a consultarse, los procesos de información sobre esos temas, las etapas y dinámicas de la consulta, y los plazos y tiempos de la ejecución de esas etapas.

\section{IMPLEMENTAR LA CONSULTA: CÓMO DEBE SER Y QUÉ SE DEBE EVITAR}

Se podría pensar que un proceso de consulta como el planteado es altamente costoso —en términos económicos - y que finalmente no garantizará que los consultados acepten determinadas decisiones o resoluciones de Estado. De nuestra propia experiencia y de aquella de la que hemos tenido conocimiento, por otras personas y organizaciones, podemos decir que en la ejecución de proyectos de desarrollo y de infraestructura generalmente no se toma en cuenta la reacción social y sus costos. Esto a la larga provoca que el monto económico del proyecto de desarrollo o infraestructura sea mayor del inicial planteado, que si se hubiera considerado como una parte del mismo el factor social y el proceso de diálogo y negociación previo, por ejemplo, el dado en San Salvador Atenco con el proyecto de nuevo aeropuerto para la ciudad de México. 
De igual forma, podemos constatar que las personas afectadas por carreteras o peor aun por proyectos tan dramáticos en su impacto como la construcción de presas, acceden cuando se les hace partícipes de las soluciones — por dónde pasará la carretera, la indemnización por árboles y hectáreas-y ven un beneficio real del proyecto: mejores condiciones de vida, vivienda, cambio de ruta, pago real y digno por daños; por el cual se sienten despojados de sus tierras.

Tal es el caso de la supercarretera Oaxaca-Istmo Huatulco, donde lo que piden los pueblos afectados es que realmente se les consulte, se consideren alternativas de paso y se les indemnice debidamente. De igual manera, son de tomarse en cuenta las experiencias de las presas Zimapan —afectando población otomí o ñhanñhu- y Aguamilpa —perjudicando a los wixaritari o huicholes- que, según Salomón Nahmad, son proyectos de presas en los que con éxito se llevó a cabo la negociación y el diálogo. ${ }^{17}$

Los frutos del proceso de diálogo y negociación en la presa Zimapan se presentan no solo por la construcción y funcionamiento de la presa, también por lo que de ello podemos cosechar para nuestra propuesta de consulta. De esta manera Nahmad (1999) plantea aspectos que resultaron de ese proceso y que nosotros apuntamos para proyectos futuros:

- Realizar estudios sociales y culturales del impacto de la presa. En nuestro caso de otros proyectos implementados por otras dependencias como la Secretaría de Comunicaciones y Transportes.

- Constituir una oficina de desarrollo social dentro de la estructura de la empresa/institución o dependencia.

- Aceptar un monitoreo y seguimiento evaluativo por una institución gubernamental responsable de la población indígena, ahora CDI.

- Aceptar la asesoría social de un experto externo adscrito un centro académico para orientar y capacitar a los equipos especializados de la Comisión Federal de Electricidad, por ejemplo perteneciente a la Universidad Autónoma Metropolitana, Universidad Autónoma de México, Centro de Investigaciones y Estudios Superiores en Antropología Social, Escuela Nacional de Antropología e 
Historia, Instituto Nacional de Antropología e Historia, Instituto de Investigaciones Antropológicas de la UNAM.

- Aceptar que la empresa/dependencia cumpla compromisos sobre la base de cinco principios generales:

- Restablecer o mejorar los niveles de vida de la gente afectada por el proyecto hidroeléctrico u otro, de manera social y culturalmente aceptable.

- Desarrollar programas de actividades productivas en participación con las dependencias involucradas.

- Realizar consultas externas con la población afectada y sus representantes.

- Definir la participación institucional en las diversas acciones que comprende el Plan. ${ }^{18}$

- Establecer políticas y niveles de indemnización acordes con los costos de restitución, de los bienes por afectar.

\section{DEVOlVER O REgRESAR LOS RESUltados}

Mencionábamos que en el proceso de diálogo y negociación para el diseño y ejecución de una consulta era necesario considerar la solicitud de los representantes de informar a sus representados sobre los avances del proceso y la información que se les haya dado. Entonces, es importante considerar los momentos de bajar la información o regresarla, según la etapa.

El plazo en la entrega final de los resultados debe ser planteado desde el principio y cumplido, de no ser así, debe informarse a través de «un propio»-funcionario o agente- sobre las causas, fijándose un nuevo plazo. No basta que la devolución sea a través de documentos impresos —relatorías, folletos, periódicos, memorias, informes-, visuales o auditivos, es fundamental que se comparta cómo se estableció el contacto, el diseño e implementación de la consulta, es decir, abrir nuevamente un espacio de diálogo y negociación. Sin embargo, no podemos decir que aquí se cierra el ciclo/proceso de la consulta, pues falta la última etapa. 


\section{SEGUIMIENTO Y VERIFICACIÓN DE LOS RESULTADOS DE LA CONSULTA}

Ahora debe regresarse a las preguntas: ¿Qué se hará con los resultados? ¿De qué manera serán utilizados e interpretados? ¿Cuál será su expresión final?; mismas que deben ser respondidas desde el principio por el Estado y sus dependencias, y que fueron sometidas a la consideración de los consultados desde los primeros diálogos. Por ejemplo, respecto de la última pregunta realizada, el Plan de Desarrollo para los Pueblos Indígenas es la expresión final de una consulta y debe ser difundido con los directamente consultados, independientemente de que se dé a conocer a otros actores o sectores, o incluso aunque se haya difundido a través de impresos debe llevarse a las comunidades y sus representantes.

Esto, de la misma manera como se estableció la confianza, se dialogó y negoció sobre el diseño y la implementación de la consulta, y cómo se regresaron los resultados. Sobre el mismo ejemplo, el seguimiento de los resultados de la consulta será el monitoreo y

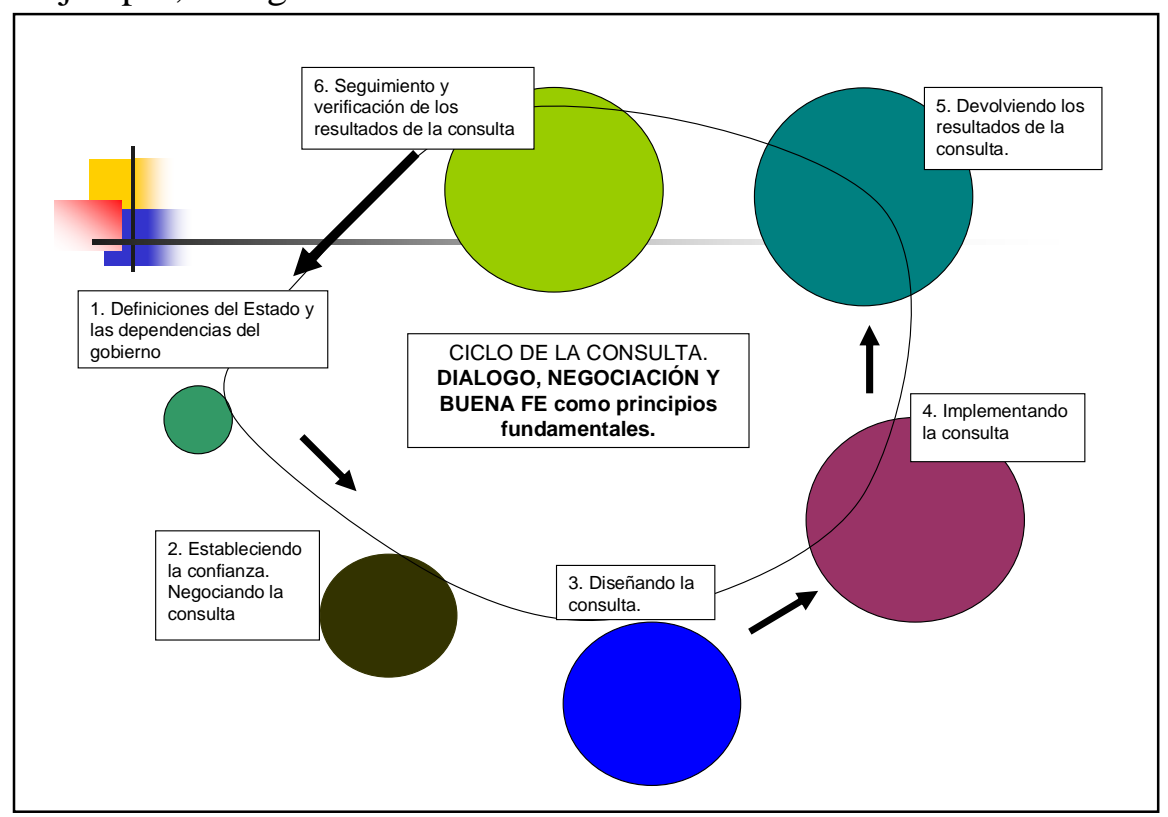

observación de cómo se da la consecución de los objetivos y metas planteados en el Plan y de los avances de su implementación en general. Se daría a través de comisiones temáticas y regionales en las que estén los representantes de los que fueron consultados, así como de otros actores relacionados con ellos: organizaciones, centros de derechos 
humanos, universidades, intelectuales, académicos. Nuevamente, la difusión de los resultados de este monitoreo debe ser llevada a los consultados de manera directa. Es entonces cuando podemos decir que el ciclo de la consulta está cerrado y la confianza reestablecida.

\section{EN CONCLUSIÓN}

Los puntos importantes a tomarse en cuenta en una iniciativa sobre consulta a los pueblos indígenas en México son los siguientes:

1. La consulta a los pueblos indígenas ha de apegarse al Convenio 169 de la OIT sobre pueblos indígenas y tribales en países independientes, en lo general, y concretamente en los artículos 6 y 7: buena fe, de manera adecuada, informada y previa al diseño e implementación de alguna medida o proyecto que les afecte.

2. Las consultas deben establecer obligaciones y acuerdos que el Gobierno cumplirá en plazos determinados y ciertos, es decir, el carácter vinculante. Por ello, han de establecerse los criterios de este carácter así como las hipótesis y alcances del mismo.

3. Como parte de la consulta, se consideraran los mecanismos de participación de los indígenas en su diseño, implementación y seguimiento.

4. Los talleres, foros de información, consultas de opinión y otros mecanismos, son herramientas que pueden ayudar a los fines que persigue una consulta —que se apegue al Convenio 169-, pero NO se pueden considerar consultas.

5. El acceso a la información sobre los temas o asuntos a consultar, la calidad de éste y el manejo que de él tengan los interesados —indígenas, pueblos indígenas y sus organizaciones-, determinarán la calidad de la consulta y, eventualmente, el cumplimiento del principio de buena fe. Esta es un requisito fundamental en cualquier acto jurídico - por ejemplo, un contrato o un testamento-, por lo que los vicios de la voluntad como el engaño o el dolo atentan contra este principio. Debe considerarse la nulidad de una consulta que no cumpla con este principio o bien, o cuando se compruebe que ha habido mala fe o algún vicio de la voluntad. 
Finalmente, el debate sobre el derecho a la consulta debe ser asumido por el Congreso de la Unión para ser legislado, con ello se daría cumplimiento al Convenio 169 de la OIT, compromiso internacional adquirido por el Estado mexicano.

Lo que se ha expresado en este artículo tiene como finalidad motivar ese debate y, sobre todo, continuar su seguimiento e investigación desde la academia y las instancias de gobierno, para abundar en las posturas institucionales y políticas de Estado — haciéndolas más efectivas y eficientes- sobre el particular y sobre los derechos de los indígenas y sus pueblos. 


\section{BIBLIOGRAFÍA}

Adame Goddard, Jaime, 1987, «Principios generales del derecho». En Diccionario Jurídico Mexicano, segunda edición, tomo 4, pp. 2542-2543. Porrúa-IIJ UNAM, México.

Álvarez Eréndira y Óscar Castro Soto, 2000, Agenda de la Reforma Municipal en México. Participación ciudadana y gobierno local. Centro de Servicios Municipales Heriberto Jara, AC, IIS UNAM, Centro de Estudios sobre la Reforma del Estado, Centro de Investigación y Desarrollo Económico, México.

Álvarez Nicanor, Guillermo y Marcelino Díaz de Jesús, 2003, «México: Contra una hidroeléctrica». En Enlace Indígena [consulta 15 de octubre de 2007].

Audefroy, Joel, 1993, «Pueblos Nahuas en lucha por la preservación del medio ambiente y su cultura». En Dialogues, Propositions, Histories (dph) pour une citoyenneté mondiale http://base.d-p-h.info/fr/fiches/premierdph/fiche-premierdph-1471.html. [consulta 15 de octubre de 2007].

Barabás Alicia M., 1995, «Normatividades jurídicas en torno a las relocalizaciones de población indígena». En Pueblos indígenas ante el derecho, coordinado por Victoria Chenaut y María Teresa Sierra, pp. 295-312. Centro de Investigaciones y Estudios Superiores en Antropología Social-Centro Francés de Estudios Mexicanos y Centroamericanos, México.

Barsh, Russel Lawrence y Krisma Bastien, 1997, Negociaciones eficaces por parte de los pueblos indígenas. Guía de acción, con especial referencia a América del Norte. Organización Internacional del Trabajo, Ginebra.

Chambers, Ian, 1997, «El Convenio 169 de la OIT: avances y perspectivas». En Derecho indígena, Magdalena Gómez, pp.123-136. Instituto Nacional IndigenistaAsociación Mexicana para las Naciones Unidas, AC, México.

Comisión Federal de Electricidad, «La Venta. Primera central eólica». En http://www.cfe.gob.mx/es/laempresa/generacionelectricidad/visitasvirtuales/laven taeoloelectrica [consulta 15 de octubre de 2007]. 
Comisión Nacional para el Desarrollo de los Pueblos Indígenas, 2003, «Consulta a los pueblos indígenas sobre sus formas y aspiraciones de desarrollo». Comisión Nacional para el Desarrollo de los Pueblos Indígenas (mimeografiado), Puebla, México.

—, 2003, «Líneas generales para el desarrollo integral de los pueblos y comunidades indígenas (documento base para la consulta. Octubre 2003)». Comisión Nacional para el Desarrollo de los Pueblos Indígenas (mimeografiado), México.

—, «Programa Nacional para el desarrollo de los Pueblos Indígenas 2001-2006». En http://cdi.gob.mx/index.php?id_seccion=7 [consulta 24 de abril de 2007].

Del Val Blanco, José, 1997, «Desde las políticas indigenistas». En América Indígena, vol. LVII, núms. 1-2, pp. 147-157. Instituto Indigenista Interamericano.

Díaz-Polanco, Héctor, 1992, «Derechos indígenas y autonomía». En Crítica Jurídica, núm. 11, pp. 31-58. IIJ UNAM, México.

Earle, Timothy, 2000, «Estado». En Diccionario de antropología, editado por Thomas Barfield, pp. 195-196. Siglo Veintiuno, México.

Ehecatl, 2003, «Inconformidad e impugnación de organizaciones de Oaxaca contra la consulta de la Comisión Nacional para el Desarrollo de los Pueblos Indígenas». En Ehecatl, boletín electrónico 15 de diciembre de 2003. México (recibido por correo electrónico en la fecha señalada, sin referencia de página de Internet).

Favre, Henri, 1999, Indigenismo. FCE, México.

Gómez Rivera, Magdalena, 1995, Derechos Indígenas. Lectura comentada del Convenio 169 de la Organización Internacional del Trabajo. INI, México.

González Saravia, Dolores, 1997, Manual de instrumentos para el manejo de conflictos. Centro de Servicios Municipales Heriberto Jara, AC, México.

Guerrero Villalobos, Guillermo, 1994, «Presentación». En Primero el Hombre. Zimapan, editado por Rafael López Jiménez, p. 6. CFE, México.

Hernández, Rosalva Aída, Sarela Paz y María Teresa Sierra (coords), 2004, El estado y los indígenas en tiempos del Pan: neoindigenismo, legalidad e identidad. Centro de Investigaciones y Estudios Superiores en Antropología Social-LIX Cámara de Diputados-Miguel Ángel Porrúa, México. 
Indicadores Socioeconómicos de los Pueblos Indígenas de México 2002 (INI).

Instituto Nacional Indigenista y Oficina de Representación para los Pueblos Indígenas, 2002, Programa Nacional para el Desarrollo de los Pueblos indígenas 20012006. Instituto Nacional Indigenista-Oficina de Representación para los Pueblos Indígenas, México.

Instituto Nacional Indigenista, Delegación Oaxaca, 2002, «Consulta nacional sobre pueblos indígenas, políticas públicas y reforma institucional. Informe general de resultados de las propuestas del estado de Oaxaca». INI Delegación Oaxaca, México.

López Jiménez, Rafael (editor), 1994, Primero el Hombre. Zimapan. CFE, México.

López Jiménez, Rafael, 1994, «El reto». En Primero el Hombre. Zimapan, editado por Rafael López Jiménez, pp. 18-33. CFE, México.

Nahmad Sittón, Salomón, 1999, «Impacto de las presas hidroeléctricas en los pueblos indígenas chinantecos, otomíes y huicholes: Un estudio de caso sobre México». En www.dams.org/kbase/submissions/showsub.php?rec=soc165 World Commission on Dams (consulta el 28 de enero de 2004).

Pérez Duarte, Alicia y Víctor Carlos García Moreno, 1987, «Buena fe». En Diccionario Jurídico Mexicano, segunda edición, tomo 1, pp. 362-363. Porrúa-IIJ UNAM, México.

Pérez Ruiz, Maya Lorena y Arturo Argueta Villamar, 2003, «No todos los indigenismos son iguales». En México Indígena, vol. 2, núm. 4, pp. 14-24. Comisión Nacional para el Desarrollo de los Pueblos Indígenas (CDI), México.

Robinson, Scott S., 1995, «La convergencia del derecho público internacional: legislación mexicana y normas jurídicas en el contexto norteamericano de la reglamentación del impacto de presas entre comunidades indígenas». En Pueblos indígenas ante el derecho, coordinado por Victoria Chenaut y María Teresa Sierra, pp. 313-341. Centro de Investigaciones y Estudios Superiores en Antropología Social-Centro Francés de Estudios Mexicanos y Centroamericanos, México. 
Robinson, Scott y José Luis Reza, 1992, Testimonios de afectados por presas hidroeléctricas en México, $3 a$ parte: Aguamilpa. (Serie Videos de apoyo a la docencia. Scott Robinson [realización, producción, guión y comentarios], José Luis Reza [colaborador]). Universidad Autónoma Metropolitana Iztapalapa, México.

Rodríguez Baños, Roberto, 1994, «El hombre es su ecología». En Primero el Hombre. Zimapan, editado por Rafael López Jiménez, pp. 69-113. CFE, México.

Servicios de Apoyo Intercultural (ed.), s/f, Acuerdos de San Andrés. Derechos pendientes. México.

Tomei Manuela y Lee Swepston, 1996, Pueblos indígenas y Tribales: Guía para la aplicación del Convenio 169 de la OIT. Organización Internacional del Trabajo, Centro Internacional para los Derechos Humanos y el Desarrollo Democrático, Ginebra.

Uphoff, Norman, 1995, «Adaptar los proyectos a la gente». En Primero la gente. Variables sociológicas en el desarrollo rural, coordinado por Michael M. Cernea, pp. 535-581. FCE, México.

\section{LEGISLACIÓN}

Código Civil Federal, 2004. En Agenda Civil del D.F. Ediciones Fiscales ISEF, México.

Código Civil para el Distrito Federal, 2004. En Agenda Civil del D.F. Ediciones Fiscales ISEF, México.

Constitución Política de los Estados Unidos Mexicanos, 2002. Colección Porrúa, México.

Ley de la Comisión Nacional para el Desarrollo de los Pueblos Indígenas. Diario Oficial de la Federación, 21 de mayo de 2003.

Ley Federal de fomento a las actividades realizadas por organizaciones de la sociedad civil, publicada el 9 de febrero de 2004 en el DOF.

Ley Federal de Transparencia y Acceso a la información gubernamental. En http//www.cddhcu.gob.mx/leyinfo/pdf/244.pdf [consulta 11 de junio de 2002], en: http//www.diputados.gob.mx/leyinfo/index.htm [consulta febrero de 2004].

Ley de Planeación (última reforma aplicada 13/06/2003), en:

http//www.diputados.gob.mx/leyinfo/index.htm [consulta febrero de 2004]. 
Revista Pueblos y Fronteras digital

Estudios, aportes y retos actuales de la antropología jurídica en México
Núm. 5, Junio-Noviembre 2008 http:// www.pueblosyfronteras.unam.mx

Organización Internacional del Trabajo, 2004, Constitución de la Organización Internacional del trabajo. En ILOLEX (base de datos sobre normas internacionales del trabajo) http://www.ilo.org [consulta 25 de febrero de 2004].

Organización Internacional del Trabajo, 2004, Convenio sobre consultas tripartitas para promover la aplicación de las normas internacionales del trabajo (entrada en vigor: 16:05:1978), en ILOLEX (base de datos sobre normas internacionales del trabajo) http://www.ilo.org (consulta 25 de febrero de 2004). 
Revista Pueblos y Fronteras digital

Estudios, aportes y retos actuales de la antropología jurídica en México
Núm. 5, Junio-Noviembre 2008

http:// www.pueblosyfronteras.unam.mx

\section{Notas}

${ }^{1}$ http://www.cfe.gob.mx/es/laempresa/generacionelectricidad/visitasvirtuales/laventaeoloelectrica.

${ }^{2}$ El 28 de febrero de 2007 dicté una conferencia magistral sobre Consulta a los Pueblos Indígenas en la Cámara de Senadores.

${ }^{3}$ De igual forma la Comisión Nacional para el Desarrollo de los pueblos Indígenas (CDI) me solicitó realizar un trabajo de investigación sobre Metodologías de consulta a las comunidades indígenas (2004). El contenido de este trabajo está dirigido a los criterios que deben de asumirse desde el Estado, y es más amplio del que ahora se presenta, sin embargo y de igual forma está basado en mi experiencia y en la reclamación mencionada, en cuya elaboración participé con otros abogados.

${ }^{4}$ Héctor Díaz-Polanco hace una crítica a los indigenismos y a las políticas indigenistas que se han dado desde la colonia hasta nuestros días: «Las diversas políticas indigenistas que han operado a lo largo de nuestra historia son el reflejo, y en varios sentidos la causa, de la heterogeneidad étnica no resuelta. Los indigenismos implican políticas concebidas y diseñadas por los no indios, para ser aplicadas a los otros; no suponen una consideración del punto de vista y los intereses de esos otros, sino una negación rotunda de que estos tengan algo que opinar sobre sus propios asuntos. Los indigenismos reúnen así la doble cualidad de ser inorgánicos — respecto a los grupos étnicos—y extremadamente homogeneizadores» (1992: 43-44). Por su parte, Henri Favre señala, lo que a mi modo de ver caracteriza la política indigenista del gobierno mexicano: «El apogeo del movimiento indigenista se sitúa entre 1920 y 1970. El indigenismo se convirtió entonces en la ideología oficial del Estado intervensionista y asistencialista, establecido durante la gran depresión y que dio los recursos necesarios para llevar a cabo el proyecto nacional ... Durante esos cincuenta años, el indigenismo orientó el curso de una política, dictó normas a la sociedad, impuso cánones a las letras y a las artes, y presidió la reescritura de la historia ... El movimiento indigenista no es la manifestación de un pensamiento indígena, sino una reflexión criolla y mestiza sobre el indio. De hecho se presenta como tal, sin pretender en absoluto hablar en nombre de la población indígena. Esto no impide que tome decisiones acerca de su destino en sus propios lugares, según los intereses superiores de la nación tal y como son concebidos por los indigenistas» (1999: 10-11). Es importante considerar que se han hecho múltiples críticas a la política indigenista, pero también se han expuesto argumentos a favor, por ejemplo José del Val, cuando era director del Instituto Indigenista Interamericano, señalaba que esas críticas han sido injustas y superficiales, pues no consideran el proyecto — motivación, misión — original de la política indigenista: «si bien la crítica al "indigenismo" ha sido abundante, detallada y en muchas ocasiones injusta y virulenta, podemos afirmar, con conocimiento de causa, que no se ha producido ésta con claridad y profundidad suficiente como para esclarecer suficientemente las causas y condiciones que nos permitan comprender seria y cabalmente este "fracaso"»(1997:149). Sin embargo, las motivaciones expuestas en Pátzcuaro, Michoacán (1940), distaron mucho de los resultados en la puesta en marcha y la ejecución de los programas gubernamentales, a través de los cuales se pretendió implementar la política indigenista o el indigenismo a favor de los indígenas; y los hechos hablan por sí solos, y en todo caso muchas organizaciones y pueblos indígenas exigen otro tipo de política y de relación con el Estado. Por su parte, Maya Lorena y Arturo Argueta definen el indigenismo como una política de Estado destinada a un sector de la población, el indígena, haciendo énfasis en una faceta del indigenismo: «el de transferencia y participación impulsada por Arturo Warman, que se propuso transferir a los indígenas las decisiones y recursos indigenistas». En este campo «se privilegió la formación y la consolidación de organizaciones a todos los niveles y se le dio un lugar especial a la formación y capacitación de cuadros indígenas, tanto técnicos como políticos». De igual forma hacen una crítica a lo que se quiere perfilar como el nuevo indigenismo - privilegiando el asistencialismo—- crítica que debe ser considerada con seriedad para no incurrir en errores o repetirlos (Pérez y Argueta 2003: 14-15, 22-23).

${ }^{5}$ El Estado es el tipo más complejo de organización de una sociedad, que implica a su vez la acción y la asociación humana: la agregación de grupos y la interacción de distintos niveles de organización — para esta definición nos inspiramos en Earle (2000: 195-196).

6 Testimonios de los directamente afectados, así como referencias de páginas web y bibliografía, se vertieron en el trabajo que en 2004 entregué a la CDI. 
Revista Pueblos y Fronteras digital

Estudios, aportes y retos actuales de la antropología jurídica en México
Núm. 5, Junio-Noviembre 2008

http:// www.pueblosyfronteras.unam.mx

${ }^{7}$ Una consulta tipo censal fue propuesta por la senadora Luisa María Calderón Hinojosa, del grupo parlamentario del Partido Acción Nacional, en un proyecto de decreto sobre la Ley de Consulta a Pueblos y Comunidades Indígenas, copia que la Dirección de procuración de justicia de la CDI nos proporcionó.

${ }_{9}^{8}$ Programa Nacional para el Desarrollo de los pueblos indígenas, p. 93.

9 Uphoff (1995: 566) apunta que la participación de los afectados por proyectos de desarrollo e infraestructura, para dar y recabar datos sobre su impacto, eleva el valor de la información, en tanto es más confiable pues en ella se toman en cuenta las necesidades y expectativas de la gente.

${ }^{10}$ Tanto el Código Civil del Distrito Federal como el Código Federal establecen los vicios de la voluntad como requisitos de anulación de un acuerdo de voluntades, de un contrato o acto jurídico. En otras palabras, ya sea un acto jurídico expresión unilateral de la voluntad, contrato o acuerdo, debe ser de buena fe, sin dolo ni coacción para que sea plenamente válido. Por tanto, una consulta de buena fe será aquella en la que las comunidades y pueblos indígenas dan su opinión, parecer, consentimiento, negativa, etcétera, con pleno conocimiento de causa, es decir, con información suficiente, clara y cabal, con comprensión del tema que se les consulta, las implicaciones a corto y mediano plazo, y saber de antemano las responsabilidades y obligaciones que el gobierno tiene o adquiere con una consulta. Un acto jurídico, ya sea la declaración unilateral de la voluntad, un acuerdo de voluntades o un contrato debe cumplir con determinados requisitos para ser plenamente válido, fundamentalmente que la voluntad que otorgan las partes en ese acuerdo o la voluntad de la persona que promete no esté viciada o afectada por la mala fe, el dolo o la coacción. Es decir, que las partes emitan con toda libertad y con plena conciencia su opinión, y en última instancia su acuerdo y voluntad.

${ }^{11}$ La buena fe como principio general del derecho. En el mismo diccionario se lee: «No es posible hacer una enumeración exhaustiva de los principios generales del derecho, pues el conocimiento de ellos se va perfeccionando poco a poco y por lo mismo su número y contenido han ido variando, sin embargo, por vía de ejemplo se pueden mencionar algunos: la equidad, o sea la prudente aplicación de la ley al caso concreto; la buena fe o lealtad a la palabra empeñada; la obligación de cumplir los convenios; el derecho de legítima defensa, o sea el de rechazar la fuerza con la fuerza, etc.». De igual forma se plantea que el fundamento de los principios generales del derecho «es la naturaleza humana racional, social y libre; ellos expresan el comportamiento que conviene al hombre seguir en orden a su perfeccionamiento como ser humano. Así, el principio de "dar a cada quien lo suyo" indica el comportamiento que el hombre ha de tener con otros hombres a fin de mantener la convivencia social; si cada quien tomara para sí lo que considera "propio" sin respetar lo "suyo" de cada quien, la convivencia civil degeneraría en la lucha de todos contra todos; en tal estado de cosas no podrían los hombres desarrollar su propia naturaleza, que es por esencia social» (Adame 1987: 2543-2542).

${ }^{12}$ Esto sucedió en la consulta en el estado de Oaxaca, 7 y 8 de diciembre de 2003, sobre el documento Líneas generales para el desarrollo integral de los pueblos y comunidades indígenas — documento base para la consulta—. Octubre 2003. De la Comisión Nacional para el Desarrollo de los Pueblos Indígenas. Según el testimonio del director del centro de derechos humanos Tepeyac del Istmo de Tehuantepec, AC, en esta «consulta» se hicieron preguntas que no se entregaron por escrito y que mencionaban expresamente el Plan Puebla Panamá, por ejemplo: ¿Está usted de acuerdo o no con el PPP?.

${ }^{13}$ Lo que sigue resume el malestar expresado por distintas organizaciones del estado de Oaxaca sobre la consulta aludida: «1) La primera fase de dicha consulta, convocada por CDI, la Secretaría de Asuntos Indígenas (SAI) y la Comisión de Planeación para el Desarrollo (COPLADE), ha demostrado que esta consulta no responde a una auténtica preocupación por el bienestar de los pueblos indígenas sino más bien es un "sondeo" disfrazado sobre la aceptación de modelos de desarrollo planeados a medida de los intereses de las grandes corporaciones multinacionales que buscan el control del comercio mundial a través de diferentes tratados comerciales y convenios, llámense Plan Millenium, Escalera Náutica o Plan PueblaPanamá. 2) Es evidente que las preguntas incluidas en la encuesta aplicada a los 70 participantes en la consulta regional buscan inducir a la aceptación de un concepto de desarrollo acorde con la visión empresarial de la actual administración foxista. 3) A pesar de que los funcionarios gubernamentales como Carlos Moreno Derbez, niegan que las obras de infraestructura que se desarrollan en la región estén relacionadas con el Plan Puebla-Panamá e incluso que se refiera a éste como un plan «fantasma» y afirme ante la desconfianza de los pueblos frente a las palpables afectaciones- «que no parten de una realidad concreta», las preguntas abordadas en la mesa sobre Desarrollo económico y globalización, de la consulta, plantea de manera directa a los consultados: «¿Estaría de acuerdo en que proyectos productivos propuestos por su comunidad fueran financiados por el Plan Puebla-Panamá?». 4) Aunque los gobiernos estatal y 
Revista Pueblos y Fronteras digital

Estudios, aportes y retos actuales de la antropología jurídica en México
Núm. 5, Junio-Noviembre 2008

http:// www.pueblosyfronteras.unam.mx

federal se empeñan en afirmar que las obras de infraestructura del Plan Puebla Panamá solo buscan beneficiar a nuestras comunidades, de la noche a la mañana nuestros pueblos se han descubierto acorralados por largos cercos de alambre colocados en las orillas de las carreteras recién construidas y que ahora les impiden el libre tránsito, con elevados cobros de cuota, la destrucción de bosques, la afectación de ríos y la devastación de antiguos sitios arqueológicos. 5) La presente consulta no toma en cuenta el verdadero sentir de los pueblos ya que al llamar únicamente a las autoridades municipales corre el riesgo de que éstas - por conveniencia partidista o personal así como por falta de información — aprueben o respalden las propuestas de desarrollo oficiales sin tomar en cuenta la opinión de los comunidades a las que representan"».

${ }^{14}$ En resumen, se podría concluir comparativamente entre las comunidades de ambas presas que: El grado de participación en el diseño del proyecto no fue claro entre las partes, los afectados casi no participaron en el diseño inicial y prácticamente ganaron su participación en ciertas áreas del diseño. No existía la intención de incluir, inicialmente por parte de la Comisión Federal de Electricidad (CFE), a los afectados en el diseño del proyecto. Los objetivos para la participación se fueron obteniendo en el curso de las negociaciones y fases de la implementación de los reasentamientos. La participación de los afectados no era un aspecto relevante en las expectativas de la CFE y no hubo gran soporte para incluir en sus planes esta alternativa. Sin embargo en el curso de la implementación fue cambiando. Costó mucho trabajo y tiempo convencer a los ejecutores del proyecto hidroeléctrico para dar el apoyo político y financiero y las decisiones a la Gerencia de Desarrollo Social y en especial a la Unidad de Desarrollo Social de las Presas. Los afectados tuvieron que aprender en el curso de las negociaciones, y sus organizaciones sociales se vieron impactadas y trastocadas por no existir un plan claro y con objetivos precisos de la participación. Aprendimos en el proceso que la participación resuelve los problemas sociales de los reasentamientos involuntarios con menores tensiones y conflictos. Los reasentamientos en ambas presas fueron menos conflictivos que las dos últimas en la experiencia mexicana, el de El Caracol en Guerrero y la del Cerro de Oro en Oaxaca (Nahmad 1999: 11). En conclusión: Se debe crear una unidad especialmente dedicada a dar curso y seguimiento al proceso de diálogo y negociación, con un equipo técnico y logístico que mida los tiempos y que tenga control de los recursos metodológicos y económicos, pero también que cuente con un círculo de especialistas, consultores, y el monitoreo de instituciones como el Banco Mundial, la OIT, el Alto Comisionado de Naciones Unidas para los Derechos Humanos o Universidades, para considerar el factor social y con ello medir y tener control de la reacción social. Debe considerarse y definirse el tipo de participación que se desea según el Estado y la que desean los consultados o ciudadanos. Esto puede ser un foco de conflicto que debe resolverse previamente. Es fundamental considerar un proceso de diálogo y negociación en cualquier espacio, donde se coloquen frente a frente gobierno y los ciudadanos.

${ }^{15}$ El caso de la presa hidroeléctrica de San Juan Tetelcingo estableció precedentes en la aplicación interna o nacional-no jurisdiccional — pues fue en negociaciones directas con el Ejecutivo Federal- del Convenio 169 de la OIT. En este caso, los pueblos nahuas afectados se organizaron en el Consejo de Pueblos Nahuas del Alto Balsas (CPNAB), impugnando la presa, haciendo uso del derecho a la Consulta y a la integridad del territorio que el Convenio 169 de la OIT establece. Para mayor información véase Pueblos Nahuas en lucha por la preservación del medio ambiente $y$ su cultura, en http://base.d-ph.info/fr/fiches/premierdph/fiche-premierdph-1471.html., en donde se señala, entre otras cosas: «Los nahuas crearon el CPNAB el 21 de octubre de 1990 con el objetivo de luchar contra la construcción de la presa hidroeléctrica. Una de las principales demandas del Consejo fue que el gobierno mexicano declarara a esta región del Alto Balsas zona de reserva ecológica. Como una primera acción, el CPNAB se propuso dialogar con el Gobierno del estado de Guerrero. Esta propuesta se concretó en noviembre de 1990 tras una marcha y un plantón frente al palacio del gobierno del estado, el Consejo consiguió una audiencia con el gobernador, pero solo para saber que el proyecto hidroeléctrico era un asunto federal. En diciembre de 1990 se concretó una primera entrevista con el presidente de la República en Iguala. Una carta que planteaba el cese de la construcción de la presa fue entregada al primer mandatario. Sin embargo, el gobierno federal no se comprometió a dar una respuesta oficial a esta petición del Consejo de los Pueblos Nahuas. Con el fin de ocupar la atención de la prensa nacional, el Consejo realizó bloqueos en la carretera México-Acapulco, marchas y jornadas de información. Una huelga de hambre fue iniciada en el centro de la ciudad de México por miembros de la comunidad Xalitla. En febrero de 1991, un representante del gobierno federal, el director del Instituto Nacional Indigenista (INI), fue designado para dialogar con el Consejo. Después de este logro se levantó la huelga de hambre. En marzo de 1991, el director del INI y algunos funcionarios de la CFE ratificaron la suspensión indefinida de la obra de la presa. El 12 de febrero de 1992, el gobernador 
del estado de Guerrero notificó al CPNBA la cancelación total del proyecto hidroeléctrico. El 13 de octubre de 1992, después de una marcha al zócalo de la ciudad de México con motivo del Quinto Centenario de la Resistencia Indígena, Negra y Popular, el presidente de la República otorgó una audiencia al CPNAB y ratificó con su firma la suspensión de la obra. En la lucha por su territorio, el Consejo de los Pueblos Nahuas ha hecho uso de un instrumento legal, el artículo 15, punto 2, del Convenio 169 de la Organización Internacional del Trabajo: «Los gobiernos deberán establecer o mantener procedimientos con miras a consultar a los pueblos interesados a fin de determinar si los intereses de esos pueblos serán perjudicados y en qué medida, antes de emprender o autorizar cualquier programa de prospección o explotación de los recursos existentes en sus tierras». De igual forma, se recomienda consultar: http://www.movimientos.org/enlacei/show_text.php3?key=2192.

${ }^{16}$ De acuerdo con el Mtro. Carlos Moreno Derbez, director de consulta de la Comisión Nacional para el Desarrollo de los Pueblos Indígenas, esta dirección ha desarrollado un Sistema Nacional de Consulta en el que se incluyen criterios sobre la representación — comunicación personal 28 de febrero de 2007.

17 Nahmad Sittón (1999). Sobre el marco jurídico de las presas y reasentamiento de los afectados, sugerimos también la lectura de los artículos de Alicia Barabás (1995) y de Scott Robinson (1995) quien por cierto filmó un video sobre el proceso de reasentamiento de los poblados afectados por la presa Aguamilpa (el video se encuentra en el acervo del departamento de antropología de la Universidad Autónoma Metropolitana Unidad Iztapalapa).

${ }^{18}$ Por lo que toca a la presa de Aguamilpa, Nahmad (1999: 10) anota «Esfuerzos y logros importantes que facilitaron la participación». En general debe reconocerse: el gran esfuerzo institucional, económico y de sensibilización social que experimentó la CFE y la evolución de las comunidades quienes aprendieron a negociar negociando. En particular se destacan como elementos positivos del proceso participativo los siguientes: Cambios institucionales en CFE. Estrategia de contratación de especialistas en ciencias sociales y desplazamiento de trabajadores sociales para vivir en la zona con las comunidades afectadas. Realización de talleres al alto nivel gerencial, con los técnicos y con la publicación de informes y en general el uso de una amplia gama de estrategias informativas por parte de CFE. Contratación del Instituto Nacional Indigenista para llevar a cabo el seguimiento y monitoreo del reasentamiento. Contratación de un experto en ciencias sociales para revisar analíticamente el proceso del reasentamiento en las dos presas. Contactos de las comunidades con grupos afectados por otros proyectos hidroeléctricos en México. Involucrar a las autoridades locales desde el inicio para incluir las obras dentro de los planes gubernamentales y asegurar la transferencia de responsabilidades una vez CFE salga de la zona. Todos ellos aspectos que pueden ser trasladados a la implementación de otros proyectos de infraestructura, así como a la implementación de una consulta y el seguimiento de sus resultados.

Fecha de recepción: 04 de junio de 2007.

Fecha de aceptación: 08 de Octubre de 2007. 